\title{
Polyphosphates of the Yeast Cell Vacuole
}

\author{
By K. J. INDGE \\ Department of Biochemistry, University of Manchester Institute of \\ Science and Technology, Manchester
}

(Accepted for publication 26 October 1967)

SUMMAR Y

The distribution of phosphorus compounds in fractions isolated from metabolically lysed yeast protoplasts by centrifugation at $2000 \mathrm{~g}$ was examined. About $40 \%$ of the acid-soluble phosphorus compounds was associated with a particulate fraction which sedimented at $2000 \mathrm{~g}$ and which was rich in vacuoles. This phosphorus was present largely as polyphosphates of relatively high molecular weights. Evidence is presented to support the view that this polyphosphate fraction is contained in the vacuole sap. The phosphorus of the crude vacuole fraction was labelled only slowly when the protoplasts were allowed to take up ${ }^{32} \mathrm{P}$-orthophosphate. The phosphorus entering this fraction appeared to be derived from precursors present in the $2000 \mathrm{~g}$ supernatant fluid fraction.

\section{INTRODUCTION}

Since the development of a method for isolating the yeast cell vacuole (Indge, $1968 b$ ) it has become possible to examine directly the composition of the vacuolar sap. Progress in this field has hitherto been limited by the relatively indirect techniques available, although significant advances have followed the application of the ultraviolet microscope to this problem (Svihla \& Schlenk, 1959, 1960; Svihla, Dainko \& Schlenk, I963, I964). Previous investigators, who used staining and other cytochemical techniques, have in some cases concluded that the yeast cell vacuole contains polyphosphate, but there appears to be no general agreement on this point (Nagel, 1948; Widra, 1959). Pfeiffer (1963) concluded that the vacuole contains phospholipids. In view of this evidence an analysis of the distribution of phosphorus compounds in the crude vacuole fraction of metabolically lysed protoplasts was undertaken.

\section{METHODS}

Preparation of protoplasts. Stock suspensions of protoplasts of the yeast Saccharomyces carlsbergensis NCYC 74 were prepared as described previously (Indge, I968a). For the preparation of protoplasts labelled with ${ }^{32} \mathrm{P}, 0.04 \mu \mathrm{c}$. $/ \mathrm{ml}$. of [ $\left.{ }^{32} \mathrm{P}\right]$ orthophosphate was added to the yeast growth medium.

Preparation of vacuoles. Vacuoles were prepared by metabolic lysis of protoplasts $\left(2 \times 10^{7} / \mathrm{ml}\right.$.) at $30^{\circ}$ in media containing mannitol $(8.5 \%, \mathrm{w} / \mathrm{v})$, glucose $(0.5 \%, \mathrm{w} / \mathrm{v})$, $0.01 \mathrm{M}$-imidazole $\mathrm{HCl}$ buffer $(\mathrm{pH} \mathrm{6.4)}$ and the tris salts of citric acid $(0.006 \mathrm{M})$ or EDTA $(0.005 \mathrm{M})$. At the end of the lysis period (about $20 \mathrm{~min}$.) samples $(8 \mathrm{ml}$.) of the suspensions were centrifuged at $2000 \mathrm{~g}$ during $4 \mathrm{~min}$. In this way the lysis products were separated into the crude vacuole fraction (2000 $\mathrm{g}$ pellet) and the $2000 \mathrm{~g}$ supernatant 
fluid fraction. The latter fraction is termed the cytoplasmic fraction in the text. The crude vacuole fraction was suspended in $8 \mathrm{ml}$. of the above solution, and the acidsoluble compounds of both fractions then extracted into trichloracetic acid (TCA) $(5 \%, \mathrm{w} / \mathrm{v})$ at $0^{\circ}$ during $4 \mathrm{hr}$.

Analytical methods. Phosphorus analyses were done radiochemically with fractions derived from ${ }^{32} \mathrm{P}$-labelled protoplasts. The total acid-soluble $\mathbf{P}$ was assayed by counting samples of the TCA extracts. Orthophosphate was counted as the molybdate complex after extraction of the TCA extracts into isobutanol + benzene according to the method of Martin \& Doty (1949). Seven-minute phosphorus, i.e. P compounds hydrolysed to orthophosphate during $7 \mathrm{~min}$. at $100^{\circ}$ in $\mathrm{N}-\mathrm{HCl}$, was similarly extracted into isobutanol + benzene and counted. Stable phosphorus compounds were estimated as the difference between the total $\mathrm{P}$ count and the $7 \mathrm{~min}$. P ortho-P-count. This assay scheme was based on the methods of Ehrenberg (I96I), Langen \& Liss (1958) and Wiame (I949).

Since mannitol can complex with molybdate and interfere in the extraction technique only I ml. samples (IO-I $5 \mu \mathrm{g}$. P) of the TCA extracts could be assayed by this method. In view of this complication the results were related to those obtained by using TCA extracts of centrifuged pellets of whole protoplasts. Such extracts, which contained only traces of mannitol, served as internal standards to monitor the assay techniques. Carrier orthophosphate $\left(40 \mu \mathrm{g}\right.$. $\mathrm{KH}_{2} \mathrm{PO}_{4}$ ) was added to each I ml. sample extracted into isobutanol + benzene solution.

The TCA-insoluble fractions were dissolved in $0.05 \mathrm{~N}$-sodium hydroxide for counting. ${ }^{32} \mathrm{P}$ was assayed by conventional liquid counting techniques by using an M6 tube (2oth Century Electronics Ltd., New Addington, Surrey), and total phosphorus was estimated colorimetrically according to Ehrenberg (196I). Samples ( $0.5 \mathrm{ml}$.) containing ${ }^{14} \mathrm{C}$ were mixed with $8 \mathrm{ml}$. of DEM phosphor (Panax Ltd., Redhill, Surrey) and counted in a Panax SC-LP scintillation counter. Potassium was estimated by flame photometry (Evans Electroselenium Ltd., Halstead, Essex) after digestion of the samples in boiling $8 \mathrm{~N}$-nitric acid. RNA was determined by the method of Mejbaum (1939), and amino acids by the method of Rosen (1957).

Gel filtration. TCA was removed from the acid extracts of the protoplast fractions by ether extraction and the samples then analysed on Sephadex G. 25 and G. 50 columns $\left(\mathrm{I}^{\circ} 5 \times 12\right.$ and $1 \cdot 5 \times 25 \mathrm{~cm}$., respectively). The samples were eluted with $0.05 \mathrm{~N}$-sodium chloride. The ability of Sephadex gels to separate polyphosphates was initially tested by using mixtures of dialysed hexametaphosphate (Allgén \& Norberg, I959) and pyrophosphate.

${ }^{32} P$-orthophosphate uptake. The protoplasts $\left(5 \times 10^{7} / \mathrm{ml}\right.$.) were incubated with trace amounts of $\left.{ }^{32} \mathrm{P}\right]$ orthophosphate $(2 \mu \mathrm{c} . / \mathrm{ml}$.) in a solution which contained mannitol (I2\%, w/v), o.o I M-imidazole- $\mathrm{HCl}$ buffer $(\mathrm{pH} \mathrm{6.4})$, potassium chloride (0.0I $\mathrm{M}$ ) and glucose $(0.5 \%, \mathrm{w} / \mathrm{v})$. These conditions appeared to be optimal for decreasing metabolic lysis to a minimum while allowing phosphate uptake to proceed. Samples of the suspensions were removed at intervals and the protoplasts harvested and washed in unlabelled medium at $0^{\circ}$. The washed protoplasts were then metabolically lysed as described above.

Materials. ${ }^{32} \mathrm{P}$-orthophosphate (specific activity $>1000 \mathrm{C} / \mathrm{g}$.) $\left[\mathrm{U}-{ }^{14} \mathrm{C}\right]$ L-lysine $\left(5.9 \mathrm{mC} . / \mathrm{m}\right.$-mole) and $\left[3^{-14} \mathrm{C}\right] \mathrm{DL}$-serine $(5.25 \mathrm{mC} / \mathrm{m}$-mole) were obtained from the Radiochemical Centre, Amersham, Buckinghamshire. 
Dry weights. Certain quantities are reported in terms of the equivalent dry weight of whole yeast. This was calculated from the protein contents of the protoplast samples, assuming no loss of protein from the yeast during protoplast formation.

\section{RESULTS}

Distribution of phosphorus in protoplasts

The yeast was grown in ${ }^{32} \mathrm{P}$-orthophosphate labelled medium and converted to protoplasts which were then lysed metabolically by the addition of citrate $(4 \mathrm{mM})$ and glucose $(0.5 \%$, w/v) to the medium. In Fig. I the flow of labelled phosphorus into the $2000 \mathrm{~g}$ supernatant fluid fraction during the metabolic lysis of the protoplasts is shown. About $20 \%$ of the total acid-soluble $\mathbf{P}$ was present in the $2000 \mathrm{~g}$ supernatant fluid fraction before glucose was added. This was presumably a result of lysis following

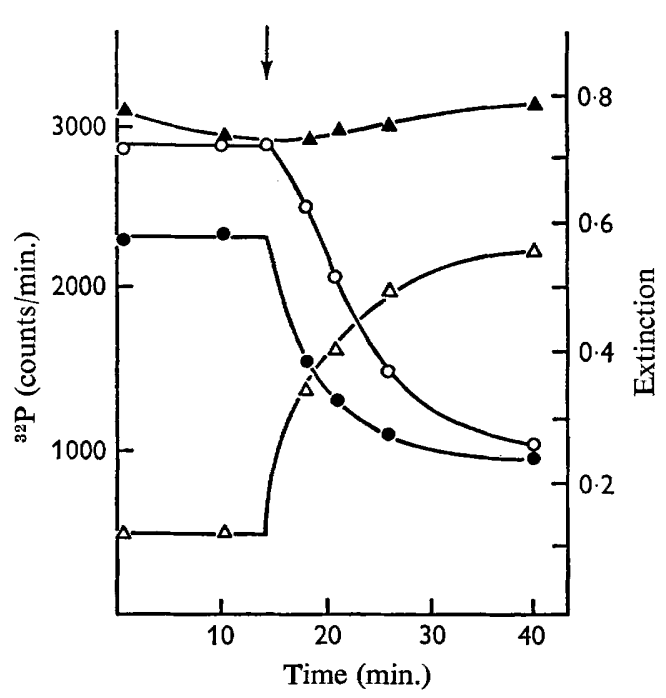

Fig. I

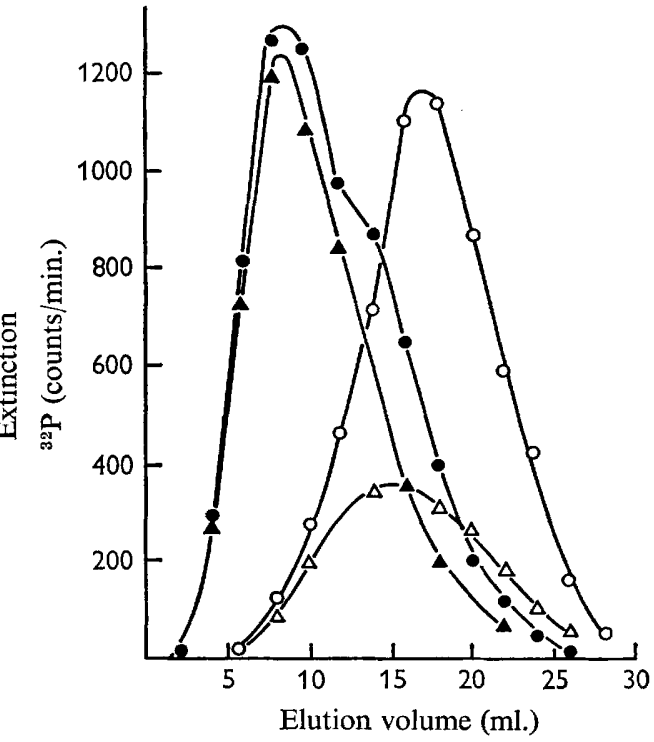

Fig. 2

Fig. I. Distribution of acid-soluble ${ }^{32} \mathrm{P}$ between the $2000 \mathrm{~g}$ supernatant fluid and pellet fractions during metabolic lysis of yeast protoplasts. ${ }^{32} \mathrm{P}$-labelled protoplasts were incubated at $30^{\circ}$ in a solution containing mannitol $(8.5 \%, \mathrm{w} / \mathrm{v})$, citrate $(4 \mathrm{mM})$, and $0.0 \mathrm{I} \mathrm{M}$-imidazole $\mathrm{HCl}$ buffer ( $\mathrm{pH} \mathrm{6.4)}$ ). Samples of the mixture were centrifuged at $2000 \mathrm{~g}$ at intervals, the fractions extracted into TCA $(5 \%, w / v)$ and the acid extracts counted. The arrow indicates the time of addition of glucose $(0.5 \%, \mathrm{w} / \mathrm{v})$. Total $\mathrm{P}, \boldsymbol{\Delta}-\mathbf{\Delta} ; 2000 \mathrm{~g}$ supernatant fluid $\mathrm{P}$, $\triangle-\triangle ; 2000 \mathrm{~g}$ pellet $\mathrm{P}, \longrightarrow$; extinction (Hilger Spekker, I cm. cells neutral filters), $\mathrm{O}-\mathrm{O}$.

Fig. 2. Fractionation of cytoplasmic and vacuolar acid-soluble phosphorus compounds on Sephadex G-25. Total $P(O-O)$ and $7 \mathrm{~min}$. $P(\triangle-\triangle)$ of cytoplasmic fraction. Total P (- $)$ and $7 \mathrm{~min} \mathbf{P}(\boldsymbol{\Delta}-\mathbf{A})$ of vacuolar fraction.

resuspension of the protoplasts in the lysis medium. After the addition of glucose and the subsequent lysis of the protoplasts, $30 \%$ of the total acid-soluble $\mathbf{P}$ was retained in the $2000 \mathrm{~g}$ pellet fraction. In this experiment the citrate concentration in the lysis medium was reduced to $4 \mathrm{~mm}$ in order to lower the rate of metabolic lysis of the protoplasts. 
The distribution and nature of the phosphorus compounds of the cytoplasmic and vacuolar fractions ( $2000 \mathrm{~g}$ supernatant fluid and $2000 \mathrm{~g}$ pellet fractions, respectively) was investigated by using five preparations of ${ }^{32} \mathrm{P}$-labelled protoplasts. It can be seen from Table I that the crude vacuole fraction prepared by metabolic lysis contained $39 \%$ of the acid-soluble $\mathrm{P}$ of the protoplasts, and that this fraction consisted largely of acid labile, $7 \mathrm{~min}$. P. This labile phosphorus was shown to represent inorganic polyphosphate by precipitation with $\mathrm{Ba}^{2+}$ at $\mathrm{pH} 4.5$ according to Wiame (1949).

It is known that the acid-soluble fraction of whole yeast cells contains $30-40 \%$ of the cell phosphorus (Juni, Kamen, Reiner \& Spiegelman, 1948). However, acid extracts of the protoplasts contained $65-70 \%$ of the cell phosphorus. About $90 \%$ of the acidinsoluble $P$ could be accounted for as nucleic acid $P$, judging from estimations of the RNA present in this fraction. The crude vacuole fraction prepared by metabolic lysis contained about $\mathbf{I} 8 \%$ of the total acid-insoluble $\mathbf{P}$ of the protoplasts. In view of the heterogeneity of the crude vacuole fraction the acid-insoluble compounds were not investigated further.

\title{
Table $\mathrm{I}$. The percentage distribution of acid-soluble phosphorus compounds in the cytoplasmic and vacuolar fractions of yeast protoplasts
}

Five separate batches of ${ }^{32} \mathrm{P}$-labelled protoplasts were disrupted by means of metabolic lysis in solutions containing EDTA $(5 \mathrm{~mm})$, glucose $(0.5 \%, \mathrm{w} / \mathrm{v})$ and mannitol $(8.5 \%, \mathrm{w} / \mathrm{v})$ at $\mathrm{pH} 6.4$. The lysates were separated by centrifugation at $2000 \mathrm{~g}$ into the vacuolar and cytoplasmic fractions and extracted with TCA. The results given are the mean values $\% \pm$ S.D. of the five determinations. The total acid-soluble $\mathbf{P}$ was about $17 \mu \mathrm{g}$. $\mathrm{P} / \mathrm{mg}$. dry weight equivalent of whole yeast.

$\begin{array}{lcrrr}\text { Protoplast fraction } & \text { Total P } & \text { Ortho-P } & 7 \text { min. P } & \text { Stable P } \\ \text { Whole protoplast } & =100 & 20 \cdot 0 \pm 2 \cdot 9 & 54 \cdot 9 \pm 8 \cdot 6 & 26 \cdot 2 \pm 6 \cdot 7 \\ \text { Vacuole } & 39 \cdot 2 \pm 6 \cdot 0 & 6 \cdot 0 \pm 1 \cdot 8 & 30 \cdot 6 \pm 4 \cdot 5 & 2 \cdot 1 \pm 1 \cdot 3 \\ \text { Cytoplasm } & 60 \cdot 2 \pm 5 \cdot 0 & 15 \cdot 0 \pm 2 \cdot 0 & 25 \cdot 3 \pm 2 \cdot 8 & 21 \cdot 3 \pm 7 \cdot 0\end{array}$

Table 2. Release of the phosphorus of the vacuole fraction of yeast protoplasts into the $2000 \mathrm{~g}$ supernatant solution

\begin{abstract}
${ }^{32} \mathrm{P}$-labelled protoplasts were metabolically lysed, the lysate centrifuged at $2000 \mathrm{~g}$ and the supernatant fluid discarded. The pellet fractions were resuspended in $10 \%(\mathrm{w} / \mathrm{v})$ mannitol solution at $\mathrm{pH} 6.4$ except where the effects of water and TCA were to be tested, and stored for $\mathrm{I} \mathrm{hr}$ at $20^{\circ}$ unless otherwise stated. The mixtures were then centrifuged at $2000 \mathrm{~g}$, the supernatant liquids extracted with TCA $(5 \%, w / v)$ and the acid extracts then counted.
\end{abstract}

$\begin{array}{lcc}\text { Treatment of vacuole } & \begin{array}{c}\text { 32P released to } \\ \text { 2000 } g \text { super- } \\ \text { natant fluid } \\ \text { fraction } \\ \text { (counts/min.) }\end{array} & \begin{array}{c}\text { Lysis of } \\ \text { vacuoles }\end{array} \\ \text { Held at } 0^{\circ} & \mathbf{1 3 2 0} & - \\ \text { Held at } 30^{\circ} & 4433 & + \\ \text { TCA } 5 \%(\mathrm{w} / \mathrm{v}) & 4285 & + \\ \text { Water } & 4233 & + \\ \text { Neutral red } 0.01 \% & 3456 & +\end{array}$

\section{Polyphosphate of the vacuole fraction}

The $2000 \mathrm{~g}$ pellet fraction contained considerable amounts of gelatinous membraneous material as well as intact vacuoles. It was possible, therefore, that the polyphosphate present in this fraction was associated with the vacuoles themselves, or was 
present in volutin granules (Widra, 1959) or adsorbed to membrane fragments. However, those conditions which brought about lysis of the isolated vacuoles (Indge, I968 $b$ ) also liberated the polyphosphate associated with the $2000 \mathrm{~g}$ pellet fraction into the $2000 \mathrm{~g}$ supernatant solution (Table 2).

Preliminary experiments using dialysis, precipitation with albumin (Katchman \& Wazer, 1954) and paper chromatography (Bernhart \& Chess, 1959) indicated that the polyphosphate of the vacuole fraction was of a greater molecular weight than that of the cytoplasmic fraction. This point was investigated in more detail using gel-

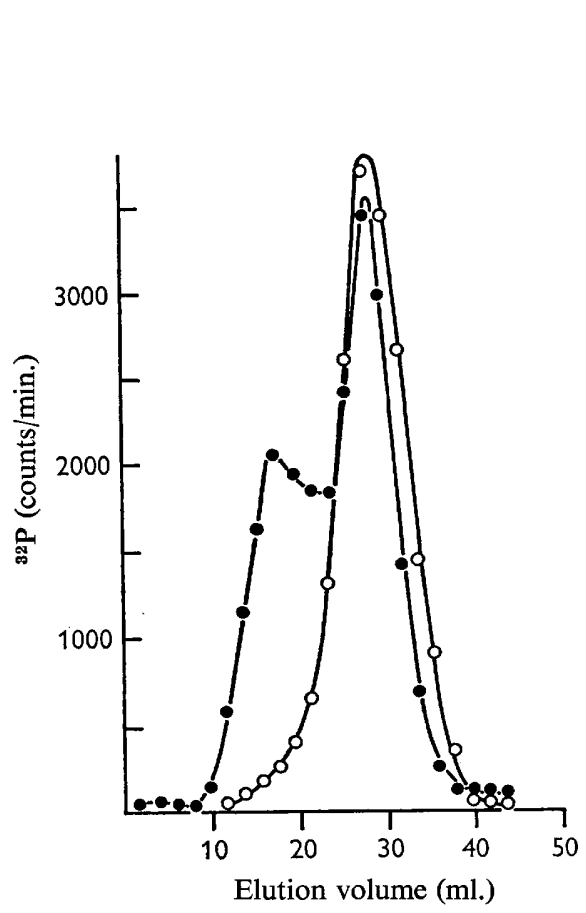

Fig. 3

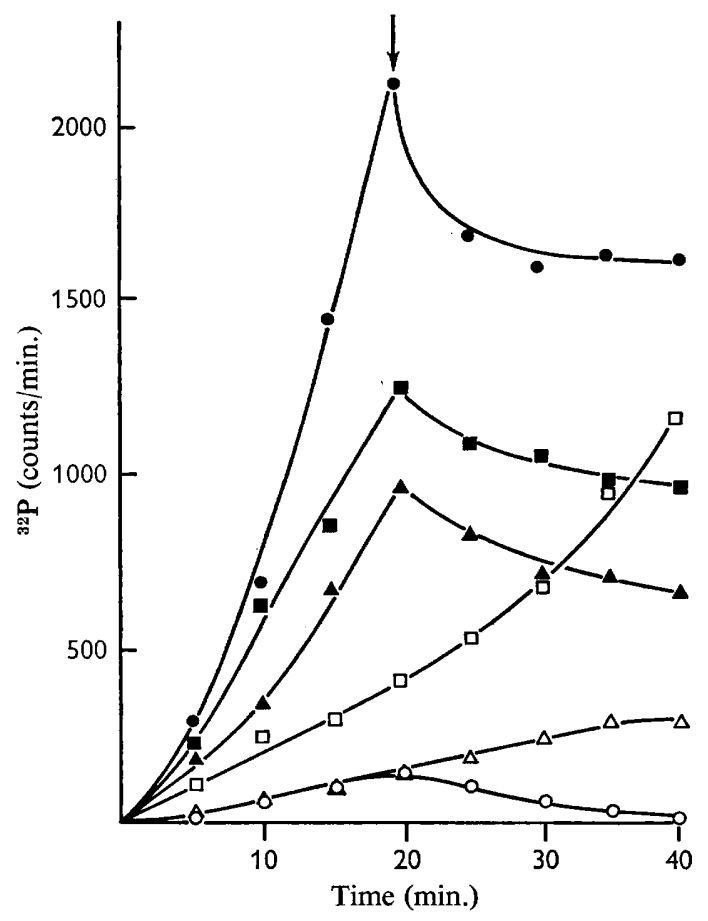

Fig. 4

Fig. 3. Fractionation of cytoplasmic and vacuolar acid-soluble phosphorus compounds on Sephadex G-50. Total $P$ cytoplasmic fraction, $O-O$. Total $P$ vacuolar fraction,

Fig. 4. Uptake of ${ }^{32} \mathrm{P}$ into cytoplasmic and vacuolar fractions of yeast protoplasts. Protoplasts were allowed to take up ${ }^{32} \mathrm{P}$-orthophosphate and at intervals samples were metabolically lysed and separated into the vacuolar and cytoplasmic fractions by centrifugation. Further details are given in the Methods section. The isotope was diluted by the addition of $100 \mu \mathrm{g}$. $\mathrm{P} / \mathrm{ml}$. as $\mathrm{KH}_{2} \mathrm{PO}_{4}$ at the time indicated by the arrow. Cytoplasmic stable-P,

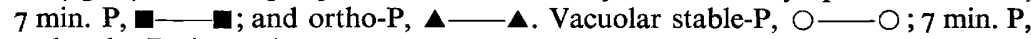
and ortho-P, $\triangle \longrightarrow \triangle$.

filtration techniques. Figs. 2 and 3 show that Sephadex G-25 and G-50 gels excluded about 70 and $40 \%$ respectively of the phosphorus compounds of the vacuole fraction. There was little evidence of high molecular weight polyphosphate in the cytoplasmic extracts. Thus the long chain-length polyphosphates of the protoplasts appeared to separate solely into the vacuole fraction. 


\section{Uptake of ${ }^{32} P$-orthophosphate}

The physiological behaviour of the two phosphorus-containing fractions separated by metabolic lysis was investigated by following the uptake of labelled phosphorus into these fractions. The rate of appearance of radioactivity in the crude vacuole fraction was considerably less than that in the cytoplasmic fraction. Some typical results are shown in the initial phase of the experiment of Fig. 4. The uptake of labelled phosphorus into the cytoplasmic and vacuolar fractions of the protoplasts, and the flow of label after the dilution of the ${ }^{32} \mathrm{P}$-orthophosphate in the medium with non-radioactive phosphate, is shown in Fig. 4. The results suggested a precursorproduct relationship between the phosphorus compounds of the cytoplasmic fraction and those of the vacuole fraction. The phosphorus compounds of the vacuole fraction did not appear to be incorporated directly from the orthophosphate of the medium. It is of interest that the uptake of ${ }^{32} \mathrm{P}$ into the orthophosphate of the vacuole fraction responded only slowly to the dilution of the isotope in the medium. This indicated that this phosphate was a genuine component of the vacuole fraction, and did not represent contamination of the fraction by the $2000 \mathrm{~g}$ supernatant fluid.

The newly synthesized ${ }^{32} \mathrm{P}$-compounds formed during these experiments were analysed by gel filtration on Sephadex G-25. There was no evidence of exclusion of the labelled polyphosphates of either the vacuolar or cytoplasmic fractions from the gel. Thus the ${ }^{32} \mathrm{P}$-polyphosphates synthesized by the protoplasts in these experiments were unlike those formed during the growth of the yeast on ${ }^{32} \mathrm{P}$-orthophosphate.

Other experiments were done with the aim of observing the turnover of these phosphorus fractions. ${ }^{32} \mathrm{P}$-labelled protoplasts were incubated with glucose in media either with or without added phosphate. These experiments did not yield useful results since there was apparently only a slow turnover of the cytoplasmic and vacuolar phosphorus fractions and the protoplasts lysed during the extended incubations which had to be used.

\section{Staining of vacuoles}

In the preceding paper (Indge, I968 b) the observations of Guilliermond (I94I) on the staining of the yeast vacuole with neutral red were repeated. Guilliermond attributed the accumulation of the dye in the vacuole to the presence of colloidal materials in the sap. A model experiment was therefore done to see whether polyphosphates present in the vacuole sap could give rise to this phenomenon. A glass microscope slide was coated with agar (Oxoid Ionagar no. $2, \mathrm{I} \%$, w/v, in 0.01 M-citrate + phosphate buffer, $\mathrm{pH} 5)$ and aqueous solutions of neutral red $(0.005-0.01 \%$, w/v) and polyphosphate $(\mathrm{r} \%, \mathrm{w} / \mathrm{v})$ were added to cups cut in the agar. The polyphosphate was prepared from hexametaphosphate according to Allgén \& Norberg (I959). Precipitation of the dye occurred in regions of the gel where polyphosphate had diffused. Orthophosphate, tripolyphosphate and tetrapolyphosphate did not cause precipitation of the dye in control diffusion tests.

\section{Other solutes present in the vacuole fraction}

On the basis of the equivalent dry weight of whole yeast the protoplasts used in this work contained $\mathrm{P} 25 \mu \mathrm{g}$. $/ \mathrm{mg}$., $\mathrm{K}^{+} 20 \mu \mathrm{g} . / \mathrm{mg}$. and amino acids $0.5-0.6 \mu \mathrm{moles} / \mathrm{mg}$. One experiment, similar to that of Fig. I, was done to measure the distribution of the $\mathrm{K}^{+}$and amino acid pools in the $2000 \mathrm{~g}$ pellet and supernatant fluid fractions separated 
after metabolic lysis. It was found that $20 \%$ of the total $\mathrm{K}^{+}$pool and $23 \%$ of the total amino acid pool separated into the $2000 \mathrm{~g}$ pellet fraction.

In one further experiment the yeast was grown in medium which contained ro $\mu \mathrm{c} . / 1$. of $\left[\mathrm{U}-{ }^{14} \mathrm{C}\right] \mathrm{L}-\mathrm{ly}$ sine or $50 \mu \mathrm{c}$. $/ 1$. of $\left[3^{-14} \mathrm{C}\right]$ DL-serine. The yeast was converted to protoplasts which were then lysed metabolically. In this case the percentages of the total radioactivity of the protoplasts isolated from ${ }^{14} \mathrm{C}$ serine-labelled yeast and ${ }^{14} \mathrm{C}$ lysinelabelled yeast separated into the crude vacuole fraction were $30 \%$ and $70 \%$, respectively.

\section{DISCUSSION}

It is suggested that the polyphosphates of the crude vacuole fraction are contained in the vacuole sap, although the evidence for this view is not conclusive. Proof of this hypothesis must await the purification of the vacuoles from the $2000 \mathrm{~g}$ pellet fraction of metabolically lysed protoplasts. However, it is difficult to account for the liberation of the polyphosphates of this fraction into solution by the various mild treatments applied (Table 2) if this is not the case. It is unlikely that volutin granules would survive exposure to the lysis medium (Harold, 1966). An alternative explanation is that the polyphosphates sedimented at $2000 \mathrm{~g}$ were adsorbed to particulate fragments of the protoplasts. Since considerable amounts of particulate material would remain in the $2000 \mathrm{~g}$ supernatant fluid fraction (Boulton, 1965) this explanation seems improbable. Weimberg \& Orton (1965), however, have suggested that part (about 30\%) of the polyphosphate of the yeast cell may be associated with the cell surface. A further possibility is that the polyphosphates are contained in vesicular structures other than the main vacuole.

The finding that the TCA extracts of the protoplasts apparently contained all the polyphosphates of the cell can be attributed to the low concentration of basic receptor groups in the extracts (Harold, 1966). It is possible that in the extraction of whole yeast cells with acid the cell wall serves to maintain a high concentration of positively charged proteins so that co-precipitation with the 'acid-insoluble' polyphosphate fraction takes place.

About $90 \%$ of the total acid-stable phosphorus compounds were found in the acid extracts of the cytoplasmic fractions of the protoplasts. This observation, taken with the results of the ${ }^{32} \mathrm{P}$-orthophosphate uptake experiments, supports the view that the vacuole serves as a repository for reserve and waste materials (Svihla, Dainko \& Schlenk, I963) and is not a region of high metabolic activity. The small amount of acid-stable $P$ found in the vacuole fraction may represent the occurrence of phosphorylated intermediates in the vacuole sap.

The polyphosphates appearing in the vacuole fraction during the ${ }^{32} \mathrm{P}$-uptake experiments were not excluded on Sephadex G-25. This finding suggested that relatively low molecular weight polyphosphates were initially synthesised in the cytoplasm and that further chain-building steps took place in the vacuole. The flow of phosphorus in such a reaction sequence would be the reverse of that observed by Langen \& Liss (1958) and by Ehrenberg (I96r). However, phosphate uptake into the various Pcontaining fractions of yeast is markedly influenced by the prior starvation of the organisms and by the phosphate concentration in the medium(Ehrenberg, 196I). In the present experiments, with protoplasts from unstarved yeast, it was necessary to use only tracer amounts of phosphate in order to achieve reasonable count rates in the 
cell fractions. Therefore these results cannot be compared directly with those obtained with starved organisms. Attempts to prepare protoplasts from such organisms were unsuccessful. The use of mercaptoethanol to prepare protoplasts from cells which are refractory to snail enzyme digestion (Davies \& Elvin, 1964; Duell, Inoue \& Utter, 1964) would appear to provide a means of overcoming this difficulty and thereby extend the scope of the present approach.

I wish to thank Professor A. A. Eddy for many helpful discussions and encouragement in the course of this work.

\section{REFERENCES}

Allgén, L. G. \& Norberg, B. (1959). A dielectric study of two acid polyelectrolytes, phosvitin and polymetaphosphate. Biochim. biophys. Acta 32, 514.

Bernhart, D. N. \& Chess, W. B. (I959). Quantitative evaluation of paper chromatograms of condensed phosphate mixtures. Analyt. Chem. 31, 1026.

Boulton, A. A. (1965). Some observations on the chemistry and morphology of the membranes released from yeast protoplasts by osmotic shock. Exp. Cell Res. 37, 343.

DAVIES, R. \& ElVIN, P. A. (1964). The effect of $\beta$-mercaptoethanol on release of invertase and formation of protoplasts in Saccharomyces fragilis. Biochem. J. 93, 8P.

Duell, E. A., INOUE, S. \& UTter, M. F. (1964). Isolation and properties of intact mitochondria from spheroplasts of yeast. J. Bact. 88, 1762 .

EhrenBerg, M. (1961). Der Phosphorstoffwechsel von Saccharomyces cerevisiae in Abhängigkeit von intra-und extracellulärer Phosphatkonzentration. Arch. Mikrobiol. 40, I26.

Guilliermond, A. (1941). The Cytoplasm of the Plant Cell. Waltham, Mass. U.S.A.: Chronica Botanica Company.

HAROLD, F. M. (I966). Inorganic polyphosphates in biology: Structure, metabolism and function. Bact. Rev. 30, 772 .

INDGE, K. J. (I968a). The effects of various anions and cations on the lysis of yeast protoplasts by osmotic shock. J. gen. Microbiol. 5I, 425.

INDGE, K. J. (I968b). The isolation and properties of the yeast cell vacuole. J. gen. Microbiol. 5I, 44I.

Juni, E., Kamen, M. D., Reiner, J. M. \& Spiegelman, S. (1948). Turnover and distribution of phosphate compounds in yeast metabolism. Arch. Biochem. 18, 387.

KATCHMAN, B. J. \& VAN WAZER, J. R. (1954). The 'soluble' and 'insoluble' polyphosphates of yeast. Biochim. biophys. Acta 14, 445 .

Langen, P. \& Liss, E. (1958). Uber Bildung und Umsatz der Polyphosphate der Hefe. Biochem. $Z$. 330, 455 .

MarTin, J. B. \& Doty, D. M. (1949). Determination of inorganic phosphate. Anal. Chem. 2r, 965.

MejBaum, W. (1939). Über die Bestimmung kleiner Pentosemengen, inbesondere in Derivaten der Adenylsäure. Hoppe-Seyler's Z. physiol. Chem. 258, II 7.

NAGel, L. (1948). Volutin. Bot. Rev. 14, I78.

Rosen, H. (1957). A modified ninhydrin colourimetric analysis for amino acids. Arch. Biochem. Biophys. 67, 10.

Pfeiffer, H. H. (1963). Cytochemische Beiträge zum Lipidvorkommen in Vacuolen. Protoplasma 57, 636.

Svihla, G. \& Schlenk, F. (1959). Localisation of S-adenosylmethione in Candida utilis by ultraviolet microscopy. J. Bact. 78, 500 .

Svihla, G. \& Schlenk, F. (1960). S-Adenosylmethionine in the vacuole of Candida utilis. J. Bact. 79, $84 \mathrm{I}$.

Svihla, G., DAinKo, J. L. \& SCHLENK, F. (1963). Ultraviolet microscopy of purine compounds in the yeast vacuole. J. Bact. 85, 399.

Svihla, G., Dainko, J. L. \& Schlenk, F. (I964). Ultraviolet microscopy of the vacuole of Saccharomyces cerevisiae during sporulation. J. Bact. 88, 449. 
WeIMRERG, R. \& ORTON, W. L. (1965). Synthesis and breakdown of the polyphosphate fraction and acid phosphomonoesterase of Saccharomyces mellis and their locations in the cell. J. Bact. 89, 740.

WiAME, J. M. (1949). The occurrence and physiological behaviour of two metaphosphate fractions in yeast. J. biol. Chem. 178, 919.

WIDRA, A. (1959). Metachromatic granules of microorganisms. J. Bact. 78, 664. 